\title{
A Study of Acquisition of /t/ by Chinese Pre-school EFL Children
}

\author{
An Ran
}

\begin{abstract}
This paper investigates the acquisition of /t/ by Chinese EFL children aged from 3 to 5 in a language school. Oral data were collected from 90 students with 30 in each age group to ensure the experimental reliability. The study process consisted of reading a word list and marking the score of each student. Target sounds were recorded for the accuracy of pronunciation by the investigators and several methods of scoring would be utilized according to the performance of the student participants for getting the most completed data. Data analysis would be done by the statistics software. All the student participants were not informed of the research purpose during the experiment. The ultimate aim of the study is to find the common features of / $t$ / acquisition by Chinese EFL children, the reasons for the occurrence of the features and to discuss the feasible learning approach for Chinese EFL children.
\end{abstract}

Index Terms-Child SLA, phonological acquisition, critical period, contrastive analysis.

\section{INTRODUCTION}

Research on phonological acquisition has typically focused on sound production, examining the development of children's oral ability to produce the segmental and prosodic structure of language. Relatively little is known about how Chinese EFL (English as a Foreign Language) children acquire English phonology and how they produce English sounds. Considering of the future, more and more Chinese parents send their young children to language schools. On this account, EFL learners in China have shown a low-age trend. Due to the mental and organs of articulation immaturity, compared with EFL adults, EFL children have shown a totally different way to learn English. Although EFL adults may have a good command of English vocabulary and grammar as a result of long-term learning experience, as for the phonological acquisition part, since children have not mastered their mother tongues in the early stage, they may utilize unique learning approaches which may exhibit particular features. Finding out the way how EFL children acquire English sounds can not only provide empirical evidence which largely supports the children phonological study, but also can contribute to the children language pedagogical theory. The purpose of this study is to offer additional information concerning how Chinese EFL children perform in the process of phonological acquisition. In this thesis, the features of acquisition of $/ \mathrm{t} / \mathrm{by}$ Chinese EFL children will be particularly investigated as a sample through a series of tests and observation and the reasons leading to these features will be discussed in the aspects of

Manuscript received January 2, 2019; revised March 18, 2019.

An Ran is with the Wuhan University, China (e-mail 517131008@qq.com). phonological acquisition and language contrastive analysis.

This paper consists of six chapters. Chapter One shows the research background and the research route. Chapter Two will show the previous study of child SLA (Second Language Acquisition) including the role of CPH (Critical Period Hypothesis) and CA (Contrastive Analysis) in child SLA. Chapter Three will demonstrate the process of the study. Chapter Four and Five discuss the results of the study and Chapter Six is a conclusion of the thesis.

\section{LITERATURE REVIEW}

This chapter first introduces a theoretical basis for the research paper with respect of two aspects, namely, critical period hypothesis and contrastive analysis hypothesis. It also briefly looks back at the achievements in the works of ESL child phonological acquisition.

\section{A. Theoretical Frameworks}

\section{1) Critical period hypothesis}

The CPH (Critical Period Hypothesis) was first proposed by neurophysiologists Penfied and Roberts (1959) from the aspect of brain plasticity indicating that the age before 10 years old was the optimal period for language learning. In 1967, the psychologist Lenneberg (1967) first applied CPH into linguistics and claimed that a critical period has often been hypothesized to exist for both first and second language acquisition. The pronunciation of foreign languages has received special attention since it seems to conform best to the critical period notion. Phonetic studies have demonstrated that non-native speakers differ from native speakers in the production and perception of specific sounds and phonetic contrasts in ways that are predictable from a comparison of how phonemes are implemented phonetically in L1(first language) and L2 (second language). In a phonetic study of five intermediate and five advanced English-speaking late L2 learners of Spanish, Colantoni and Steele (2006) [1] investigated one specific area of phonological acquisition: stop-liquid sequences. Despite this obvious limit in scope, the study surpassed most other $\mathrm{CPH}$ studies in its high degree of detail and scrutiny.

Foreign accent studies have provided evidence that the age at which an L2 is learned will influence how well an L2 is pronounced. According to Abrahamsson and Hyltenstam's reaserch, "SLA is constrained by the maturation of brain, only a small minority of bilinguals who had started their SLA after 12, but a majority of those with an age below this" (2009, p. 249) [2]. Although the development of brain will influent SLA, it is still believed that it is an age limitation that effect L2 acquisition.

Although whether CPH is tenable in SLA is still arguable, 
Bohgaerts et al. (1997) [3] have investigated the immigrants of different ages and found that younger immigrants could achieve a higher level of pronunciation and intonation than those immigrants who are adults. Those who have immigrated before 6 years old could even achieve the level of native speakers' pronunciation because younger learners would generally receive more and more varied input from native speakers and would be more highly motivated to acquire the L2 at a nativelike level. Scovel (1988) speculated that there is a critical period for the acquisition of the pronunciation of a second language only because pronunciation is "the only aspect of language performance that has a neuromuscular basis" that requires "neuromotor involvement," and has a "physical reality" (p.101). He predicted that learners who start to learn an L2 later than age 12 will never be able "to pass themselves off as native speakers" and will "end up easily identified as nonnative speakers of that language" (p.185). He also insisted on the idea that it is impossible to achieve an authentic, nativelike pronunciation of a foreign language after a specific biological period of time. Despite the fact that some ideas of Scovel are extreme, it is undeniable that $\mathrm{CPH}$ may work in both L1 and L2 learning because younger learners do perform better in many linguistic aspects than those who start to learn L2 in older ages. Flege (1989) [4] studied that native speakers of Spanish who learned English by the age of 5-6 years, but not those who learned English as adults, matched native speakers' VOT (Voice Onset Time) values for $/ t /$. Through his study, the younger learners react to the subtle sound more sensitively than the adult learners so he concluded that foreign accents are largely perceptually based.

\section{2) Contrastive analysis hypothesis}

CA (Contrastive analysis) is the systematic study of a pair of languages with a view to identifying their structural differences and similarities. It was used extensively in the field of SLA in the 1960s and early 1970s, as a method of explaining why some features of a target language were more difficult to acquire than others. According to the behaviourist theories prevailing at the time, language learning was a question of habit formation, and this could be reinforced or impeded by existing habits. Therefore, the difficulty in mastering certain structures in an L2 depended on the difference between the learners' L1 and the language they were trying to learn. Lado (1957) first formulated the theoretical foundation of $\mathrm{CAH}$ (Contrastive Analysis Hypothesis) stating that those elements which are similar to the learner's native language would be simple for him, and those elements that are different would be difficult. $\mathrm{CAH}$ involves describing the languages and comparing them and predicting learning difficulties.

Having done an experiment, Flege et al. (1992) [5] found that Chinese learners of English are often unable to produce a perceptually effective contrast between phonologically voiced and voiceless stops in the final position of English words. Through CAH, they predicted that although Chinese contrasts voiced and voiceless stop consonants in other word positions, stop consonants do not occur word-finally. Therefore, Chinese does not have a stop consonant voicing contrast word-finally, and the English word-final stop consonant voicing contrast is novel for Chinese learners of English. Similar results were also discovered in Broselow's study (1998) [6]. In his experiment, Chinese English learners were asked to read some English words and the percentage of accuracy of pronunciation were calculated. According to the results, the subjects did indeed have considerable difficulty with those codas that do not occur in Chinese - of a total of 180 final stop tokens, $81 \%$ of the voiceless stops and $98 \%$ of the voiced stops were produced incorrectly. So he drew the conclusion that the differences between two languages play as constrain factors as interlanguage when Chinese English learners are pronouncing English codas that do not occur in Chinese.

\section{B. Previous Studies on ESL Child Phonological Acquisition}

ESL (English as a Second Language) child phonological acquisition studies were focused on native foreign kindergarten children and bilingual children.

In a work of Lord (2005), English phonetic pedagogy for Spanish children was discussed in a way of comparing differences between English and Spanish. Several phonological differences between English and Spanish were investigated to see what the main reasons were for Spanish children pronouncing English with Spanish accent. It can be concluded that for Spanish children, we can in fact teach pronunciation and it may be beneficial for students to engage in self-analysis to make them aware of their own pronunciation with voice analysis programs or self-analysis project. On the pedagogical aspect, L2 classes should strive to incorporate these kinds of activities into our curricula, not just in a phonetics course but also in any L2 classroom. Giambo and McKinney (2004) [7] connected oral English proficiency with phonological awareness and English reading ability. In their experiment, they display a fact that Spanish kindergarten children in the phonological awareness group showed greater gains in oral English proficiency scores than did the children in the story-reading group, a change in oral English proficiency can be significant accounted for by change in phonological awareness. The development of phonological awareness would not only promote the reading ability, but also give positive effect on the overall oral proficiency.

Knell et al. (2007) did the first survey in Chinese background to see to what extent that Chinese pinyin would influent the acquisition of English phonetics and phonology. According to the survey, mainland Chinese EFL students who have mastered pinyin may have an advantage over Chinese-speaking children who have not mastered a mediating alphabetic system when learning to read English. Although pinyin was adopted in China in order to help children acquire Chinese characters more easily, it may also prove to be advantageous when children learn to read English words because knowledge of pinyin increase students' phonological awareness and letter knowledge, it may enhance their ability to map sounds to subsyllabic segments. It is clear that no matter how old the child is, once he has learnt pinyin, he may perform better than those younger children who have not mastered pinyin yet at least in the phonological acquisition aspect. Leahy (1980) implemented a practical approach for teaching ESL 
pronunciation base in distinctive feature analysis according to an experiment for Arabic, Farsi, Japanese and Spanish children. He found that the key measure to distinct the English pronunciation between children from different countries does not lie purely in the phonetic realization of the consonant, but in the interplay between the final stop consonant and the preceding vowel.

It seems that the language background of speakers and listeners have also been shown to be critical factors in determining the intelligibility of speech. Previous studies on ESL child phonological acquisition are mainly focus on how phonological acquisition affects the whole English oral proficiency and establish the connection between English phonological acquisition and L1.

Most of previous ESL child SLA studies focus on the overall comparison between English and mother tongue to analyze the whole phonological systems of the two languages. In this thesis, one sound in English will be emphasized to make more specific research to see how Chinese EFL children pronounce it.

\section{METHOD}

\section{A. Setting}

This study was conducted as part of bachelor's degree thesis to study the acquisition of /t/ by Chinese pre-school EFL children. The language school had an enrollment of $100 \%$ Chinese EFL children, with an enrollment of $40 \%$ Chinese children in kindergarten, $40 \%$ Chinese primary school students and 20\% Chinese middle and high school students. Having been established in 1965 in Sweden, the language school has more than 40000 employers around the world now. Half of the English teachers in the language school are foreigners with $40 \%$ of them are English native speakers. The chosen language school site was a branch of the language school focusing on children English education located in a higher-income area of a developing city in the central part of China. All the classes in the school were English immersion.

\section{B. Participants}

\section{1) Teacher participants}

Within the school, six teachers teaching EFL children English participants expressed the willingness to participate in the study after the investigators presented the purpose and the overall procedures to them at the beginning of the study.

\section{2) Student participants}

90 Chinese EFL children in the language school, including 54 boys and 36 girls, were chosen as the subjects randomly. The students were divided into three groups according to their ages $(3,4$, and 5$)$. The student participants were assessed at the same level in the language school where they attended the same level lessons and spent the same time in the language school every week ( $2 \mathrm{~h}$ per week) and there was no Chinese instruction during their lessons. None of them had learned English in the formal classrooms in other institutions such as kindergartens (as their parents claimed). All the student participants were average or above in intelligence. There was no history of problems with articulation or hearing, or left-handedness. None had traveled abroad or had been otherwise immersed in a foreign language or claimed to have received some form of phonetic training (such as a phonetics and phonology or pronunciation course) before they started the lessons in the language school. In addition, the student participants started the lessons at the same time in the language school (November, 2016). All of them speak Chinese at home.

\section{Procedures}

Oral one-to-one interviews were administered to each of the teacher participants, student participants and their parents to ensure the English level of each student participants was at the same before the word list was shown. The interview lasted for about 5 to 10 minutes.

The word list consists of $60 / \mathrm{t} /$ words in which /t/ sound are in different places. The purpose of the word list is to test how children pronounce $/ t /$ in different places. The sound of /t/ would be particularly focused. For not allowing the subjects to be aware the purpose of the study is essential, some irrelevant words would be added to the word list I. Word list II, the additional word list, was shown to the subjects. Since most of the students were too young to recognize words without pictures, each student was shown a packet of cards. The cards with pictures and designed words would be helpful and the order of the cards was placed according to word list II. The word lists will be seen on the appendix.

The students were asked to read each word on the card. If there was no error in the pronunciation of the word, the student would be given two points. If an error in the pronunciation were made, the correct pronunciation would be given by the teacher and the student would be asked to repeat the word. If the student corrected the pronunciation, then one point would be given. If, however, the student still had difficulty with the word, no point would be given. There were five groups of words of which $/ t /$ occur in different places and the full mark of each group was 12. The performance of each subject would be recorded on the interview work sheet. Only target words (words on word list I) would be marked.

The mean score of each group will be measured by the total score and the number. For example, the mean score of 3 year-old group is the total score of 3 year-old group being divided by the number of 3 year-old group. The Standard Deviation (SD) will be calculated from the mean score of each group and the score of each student. The standard deviation is found by taking the square root of the average of the squared deviations of the values from their average value to qualify the variation or dispersion of a set of data value. For example, the mean score of 3 year-old group is 5 and there are 3 students in the group, their score is 4,5 , and 6 respectively. First, calculate the deviations of each data point from the mean, and square the result of each:

$$
(4-5)^{2}=1 ;(5-5)^{2}=0 ;(6-5)^{2}=1 ;
$$

Than SD of this group is $\sqrt{(1+0+1) \div 3} \approx 0.81$. A low standard deviation indicates that the data points tend to be close to the mean (also called the expected value) of the set, while a high standard deviation indicates that the data points are spread out over a wider range of values. In order to avoid the errors, all the calculations will be done by the 
statistics software. The results of the experiment will be seen in the next chapter.

\section{RESULTS}

In this chapter, the results of the experiment will be shown according to the age and the features of words. Children perform differently when $/ t /$ is placed in different positions of the words.

\section{A. Age}

The means of five-year-old participants performed best: over 9 scores in the majority of the tests $(M=9.33, M=9.37$ and $M=9.1$ ) except $/ t /$ in the final position and specials words $(M=4.83$ and $M=7.9$ respectively). There is no significant difference between standard deviations; all of them are around 2 but it is still noticeable that the maximum standard deviation of each test is in three-year-old participants except $/ \mathrm{t} /$ in the final position (four-year-old group, $\mathrm{M}=3.13, \mathrm{SD}=1.96$ ). The results indicate a trend that older children performed better than younger no matter in what measures as well as a relatively more equal English speech ability within the age range of 3 to 5. Along with the growth of the age, children can pronounce the words with higher accuracy without correction or hints.

\section{B. Places of $/ \mathrm{t} /$}

Table 1 shows the participants' performance to pronounce words when / $t$ / in different positions. With the exception of phonological acquisition, when $/ t /$ is in the initial, second and middle sounds, the means of scores of participants are at an average level (from $M=7.63$ to $M=9.37$ ). However, when $/ \mathrm{t} /$ is placed in the final position, the scores are extremely low in three groups $(M=2.47, M=3.13$ and $M=4.83)$. In this pattern, most participants lost their scores because they cannot utter the voiceless stop $/ t /$ in the final position or transferred /t/ to /d/ as a voiced stop to utter it even they have heard the correct pronunciation for many times. Also in this test, the standard deviations are lower than 2 $(\mathrm{SD}=1.80, \mathrm{SD}=1.96$ and $\mathrm{SD}=1.51)$, which means that when $/ t /$ is in the final sound, the phonological ability is at the closest level regardless of learners' ages. It should be acknowledged that the reason why the scores in special words are not at an average level $(M=6.43, M=6.83$ and $\mathrm{M}=7.9$ ) is because the student participants claimed that some words in this word group had not been learned yet.

\section{DISCUSSIONS}

In this chapter, the features of how Chinese EFL pre-school children pronounce /t/ will be discussed in three aspects: critical period, contrastive analysis between English and Chinese and what errors can we predict when Chinese EFL pre-school children are acquiring English sounds.

\section{"Critical Period" in Second Language Phonological Acquisition}

It seems that in this study, CPH plays less influence because all the children are within the period (3-5 years old). Although some people still argue that $\mathrm{CPH}$ only exists in L1 acquisition, many of the cases have proved that "learners who started to acquire an L2 before the close of the critical period were hypothesized to be able to achieve nativelike mastery, provided that they were continuously exposed to sufficient input from native speakers of the language, especially in the immersion class" (Bongaerts, Planken, \& Schils, 1997, p.448). Human speech learning ability might be bounded by a specific period of sensitivity to environmental stimulation no matter the stimulation is the sound or the picture. Since in the early stage of learning English, children tend to use pictures to memorize words and sound, without abundant knowledge, the sensitivity to the external cue during learning process might be significant for young children.

\section{A. The Differences between English and Chinese in Second Language Phonological Acquisition}

The most significant reason may lie in the CA between English and Chinese. Because native language may pose negative transfer while learners are learning the second language, the phonological and phonetic differences may be the main reason to generate the low scores when $/ t /$ is in the final position. Chinese speakers may have difficulty with obstruent codas because obstruent codas do not occur in their native language as Liu (2008) has mentioned in the book, "The lack of terminal consonants in Chinese often presents a major phonological problems to Chinese learners of English resulting often in final consonant deletion, consonant cluster simplification (especially in word-final position)" (p.39), the noticeably "half-uttered" and "unfinished" English words may come from Chinese CV lexical formation because in Chinese words, no consonant in the final position.

Besides this reason, another difficulty for children to utter $/ \mathrm{t} /$ in the final position can be analyzed from the phonology system.

The question of what to do about voicing errors must be analyzed from two perspectives: the position and the type of sound involved. As we can see, the contrast between / $t /$ and /d/ in English is whether vocal cord vibrates; however in Chinese, the basic difference between $/ \mathrm{t} /$ and $/ \mathrm{d} /$ is whether the aspiration is strong. Since there is no aspiration contrast of $/ \mathrm{t} / \mathrm{and} / \mathrm{d} / \mathrm{in}$ English and the place of articulation organ of $/ \mathrm{t} /$ in Chinese is a little bit frontal than that in English, without fully developed organs, children may utter $/ \mathrm{t} / \mathrm{as}$ a voiceless sound with some difficulties in English because they have not been accustomed of the new places of the articulation organs. Also, during the process of phonological acquisition, as in Broselow's research, Chinese speakers may choose a simplification strategy as "deletion of the coda stop such as [vIt] pronounced as [vI]" (1996, p.263) avoiding to utter the obstruent codas. It seems that not only for Chinese EFL children, but also for adults, the absence of obstruent codas is more like an instinct rather than an error.

\section{B. Phonological Error Prediction in Child Second Language Acquisition}

During the way of language acquisition, children may pronounce words with more errors than adults' expectation because the immature learning cognition and organs development. As Pertz and Bever have found, "a phonetic change occurs when the child fails to suppress some innate process which does not apply in the standard language" 
(1975, p.150), in another word, when children realize that the phonetic features may not be suitable for the current pronunciation habits, the error may occur as a function to assist children to adapt the new phonetic system. As "omissions occur in final position comparatively often, while in initial and medial position substitutions are made frequently and omissions are rare" (Moskowits, 1970, p.429)[8], even when children are acquiring L1, the omission of obstruent coda is common because consonants are less stable in final positions than either initially or medially. Here is an example for explaining this phenomenon (Peccei, 2002, p.61) [9]:

Target word: cat

Adult's version: /kat/

Child's version: /ka/

It is a quite common tendency in early speech, especially in the beginning stage that where an adult word ends in a consonant sound, the child is deleting the final sound in his own pronunciation. For Chinese EFL children who have not finished the study of L1 phonetic system, during the study of English sounds as a new phonological system, it is inevitable to make errors which are common in both native speakers and Chinese EFL.

In summary, phonological errors of child SLA can be predicted in two ways, one is to analyze the common errors made by children who are native speakers during their speech development, the other is to study the phonological differences between L1 and L2 as we have mentioned in the previous part. This study leads to the prediction that speakers of an L1 without word-final stops will not relate English word-final stops perceptually to word-medial or word-initial stops in their L1.

\section{CONCLUSIONS}

In this thesis, the results of a research study that investigated the acquisition of / $t$ / by Chinese EFL children are examined. It is found that regardless of age, Chinese EFL children have difficulty to produce $/ t /$ in the final position. The negative effects of differences, especially in the phonetic system and phonological aspects between L1 and L2 on SLA are affirmed, and some errors that native children make when they are acquiring mother tongue may also occur in the SLA when Chinese children are learning English. However, given the comparisons between ages and results, it is found that relatively older children have a better reaction to the word pronunciation and phonological awareness, which may give a positive effect when they are learning English.

When research in child L2 phonological acquisition was carried out in a framework in which critical period and CA were viewed as the significant features to influent the learning efficiency and language errors, one question arose: How to decide to optimal time to learn L2 and what pedagogy is the best. This study is illuminating to bridge the gap between CA study and child SLA and lends support to the child phonological acquisition in the development of learning English sounds for young Chinese-speaking children who are primarily English learners but the optimal age for learning and learning approach is different by individual. Furthermore, whatever the ultimate cause of such Chinese EFL children's phonological acquisition phenomenon, it is hoped that this study invites further investigation into child second-language speech learning in particular, and into the processes underlying language learning in general.

\section{REFERENCES}

[1] L. Colantoni and J. Steele, Native-like Attainment in the L2 Acquisition of Spanish Stop-liquid Clusters, MA: Cascadilla Proceedings Project, 2006.

[2] N. Abrahamsson and Hyltenstam, "Age of onset and nativelikeness in a second language: Listener perception versus linguistic scrutiny," Language Learning, vol. 5, pp. 249-360, August 2009.

[3] T. Bohgaerts, C. V. Summerren, B. Planken, and E. Schils "Age and ultimate attainment in the pronunciation of a foreign language," Studies in Second Language Acquisition, vol. 19, pp. 447-456, 1997.

[4] J. E. Flege and C. Wang, "Native language phonotactic constraints affect how well Chinese subjects perceive the word-final English /t/-/d/ contrast," Journal of Phonetics, vol. 14, pp. 299-315, July 1989.

[5] J. E. Flege, M. J. Munro, and L. Skelton, "Production of the word-final English /t/-/d/ contrast by native speakers of English, Madarin and Spanish," Journal of the Acoustical Society of America, vol. 2, pp. 128-143, September 1992.

[6] E. Broselow, S. Chen, and C. Wang, "The emergence of the unmark in second language phonology," Studies in Second Language Acquisition, vol. 20, pp. 261-280, July 1998.

[7] D. A. Giambo and J. D. Mckinney, "The effects of a phonological awareness intervention on the oral English proficiency of Spanish-speaking kindergarten children," TESOL Quarterly, vol. 38, pp. 95-117, January 2004.

[8] A. I. Moskowits, "The two-year-old stage in the Acquisition of English phonology," Language, vol. 46, pp. 426-441, February 1970.

[9] J. S. Peccei, Child Language, $1^{\text {st }}$ ed. Beijing: Foreign Language Teaching and Research Press, 2002, ch. 3, pp. 40-51.

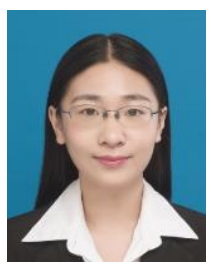

An Ran is the first and the only author of "A Study of Acquisition of /t/ by Chinese Pre-School EFL Children". An Ran was born in Wuhan, China in 1st, 12, 1994. An Ran got her bachelor's degree in Wuhan University, the department of Foreign Language and Literature in 2017 in Wuhan. Now An Ran is studying for her master's degree in Wuhan University, the department of Foreign Language and Literature in the branch of linguistics. An Ran's major directions are second language acquisition and applied linguistics. An Ran will finish her master's degree in 2020. During An Ran's undergraduate study, she also got the certification of psychology in Huazhong Normal University in China as a miner degree.

She worked as a teaching assistant in EF education first cooperation during November, 2016 to April 2017 in internship period. She interned in Nippon Express-Global Logistics Company in the summer of 2014. She published three essays during her undergraduate study:

"The interaction between English and Japanese vocabularies," English on Campus, vol. 18, pp. 200-01, June, 2016.

"The comparative philosophy between transcendentalism and Confucianism," Educational Modernization, vol. 12, pp.88, July, 2016.

"The compound policy in China," Modern Business Trade Industry, vol. 23, pp. 156-57, July, 2016.

The essay "The comparative philosophy between transcendentalism and Confucianism" was awarded the first prize for the 11th China National Education And Science Research Competition. 